\title{
VALIDATION OF THE GLOBAL PRECIPITATION MEASUREMENT MISSION CORE OBSERVATORY OVER GREAT BRITAIN AND IRELAND
}

\author{
Daniel Watters ${ }^{a}$, Alessandro Battaglia ${ }^{a, b}$, Kamil Mroz $^{b}$, Frédéric Tridon $^{a}$ \\ ${ }^{\text {a} E a r t h ~ O b s e r v a t i o n ~ S c i e n c e ~ G r o u p, ~ D e p a r t m e n t ~ o f ~ P h y s i c s ~ a n d ~ A s t r o n o m y, ~}$ \\ University of Leicester, Leicester, UK \\ ${ }^{b}$ National Centre for Earth Observation, University of Leicester, Leicester, UK
}

\begin{abstract}
This study compares the instantaneous surface rain rate estimates over Great Britain and Ireland (GBI) from the spaceborne dual-frequency precipitation radar (DPR) and the GPM microwave imager (GMI) on board the GPM Core Observatory (GPM-CO) to estimates from the ground-based United Kingdom Meteorological Office's ground-radar network. In particular, the version-5, level-2 DPR and DPR-GMI (CMB) combined products ( $5 \mathrm{~km}$ resolution) and the Radarnet 4 radar composite product ( $1 \mathrm{~km}$ resolution) are used for the three year study (May 2014 - April 2017). Products are collocated both temporally and spatially, and subject to quality control, prior to the comparison where the Radarnet product is considered to be the "ground truth". The GPM products are found to underestimate the surface rain rates detected by the Radarnet product from a sample of 575512 collocated $5 \mathrm{~km}$ data. The CMB product (bias $-2 \%$ and correlation 0.49 ) performs better in comparison to the DPR product (bias $-17 \%$ and correlation 0.42 ). Large standard deviations of around $132 \%$ suggest that the results are highly variable.
\end{abstract}

Index Terms - GPM, Radarnet, Met Office, Validation, Britain

\section{INTRODUCTION}

The NASA-JAXA Global Precipitation Measurement Mission Core Observatory (GPM-CO) satellite's launch in February 2014 [1] offers an unprecedented opportunity of monitoring precipitation over Great Britain and Ireland (GBI), both from ground-based and space-borne perspectives. Prior to this date, the predecessor satellite mission (Tropical Rainfall Measuring Mission, TRMM) only provided a tropical coverage $\left(37^{\circ} \mathrm{N} / \mathrm{S}\right)$ [2], whereas the GPM-CO now covers the

The work done by Daniel Watters was funded by UK NERC CENTA. The work done by Alessandro Battaglia and Frédéric Tridon was funded by the project "Calibration and validation studies over the North Atlantic and UK for the Global Precipitation Mission" which was funded by the UK NERC (NE/L007169/1). The work by Kamil Mroz was performed at University of Leicester, under contract with the National Centre for Earth Observation. mid-latitudes too $\left(68^{\circ} \mathrm{N} / \mathrm{S}\right)$ in a non-sun synchronous orbit [1]. The GPM-CO carries both the dual-frequency precipitation radar (DPR) and the GPM microwave imager (GMI) [3]. The DPR measures precipitation with a minimum detection threshold of $0.2 \mathrm{mmh}^{-1}$ and a $5 \mathrm{~km}$ horizontal resolution, at $\mathrm{Ka}(35.5 \mathrm{GHz})$ and $\mathrm{Ku}(13.6 \mathrm{GHz})$ frequencies over swaths of $120 \mathrm{~km}$ and $245 \mathrm{~km}$ respectively. The GMI has a swath of 885 $\mathrm{km}$, though the central region aligns with the DPR frequency swaths, and uses 13 frequency channels between $10 \mathrm{GHz}$ and $183 \mathrm{GHz}$ [1]. Ground-based precipitation measurements at C-band frequency are provided by the United Kingdom (UK) Meteorological Office radar network, made up of 18 radars (15 in the UK, 2 in the Republic of Ireland (ROI) controlled by Met Eireann, and 1 in Jersey). The measurements from each radar are composited using the Radarnet 4 system [4] and corrected using rain gauges [5].

The GPM-CO provides snap-shot measurements around the world multiple times per day. These measurements are spatially-advantageous due to their global coverage, though the ground-based Met Office measurements are temporallyadvantageous due to their constant focus within the GBI region. These measurements over GBI can be compared via temporal and spatial collocation, and the GPM-CO data products can be validated against the "ground-truth" Radarnet products from the Met Office radars.

Within this study, a collocation of all measurements over GBI in the period May 2014 - April 2017 to $5 \mathrm{~km}$ horizontal resolution is performed using the Radarnet composite surface rainfall product (natively $1 \mathrm{~km}$ ) and the level-2, version 5 GPM DPR and DPR-GMI combined (CMB) estimatedsurface rainfall products (natively $5 \mathrm{~km}$ ). Validation of the GPM products is assessed, with the aim to determine the reasons for any inconsistencies between the Radarnet and GPM products.

Three years of data are used to ensure a significant number of precipitation events are considered. The selected GPM products are used as they are sufficiently mature and are fundamental to the production of other constellation products. GBI has been chosen as a testbed for this study because it consists of two mid-latitude islands with land, coast and ocean 
regions and a light-rain climatology, where most precipitation occurrences have intensities of less than $5 \mathrm{mmh}^{-1}$ [6], suitable for assessing the minimum detection threshold of the GPM$\mathrm{CO}\left(0.2 \mathrm{mmh}^{-1}\right)$. Only one previous study has performed a validation of GPM measurements over a region including GBI [7]; this involved a three-year comparison of precipitation estimates using the GPM DPR Ku-band, GMI and other constellation radiometer measurements, and ground-based radar networks collocated to $15 \mathrm{~km}$ resolution. The DPR Ku and GMI products had biases of $-25 \%$ and $-22 \%$ respectively, and correlations of 0.49 and 0.53 respectively, suggesting that satellite instruments tend to underestimate precipitation over Western Europe.

\section{DATA AND METHODOLOGY}

\subsection{GPM Data}

The level-2A DPR and level-2B CMB GPM products, processed by the NASA Precipitation Processing System (PPS), are freely provided by [8] and details regarding the products are available from [9]. The products are produced on a $5 \mathrm{~km}$ resolution grid that matches the DPR swath pattern of $245 \mathrm{~km}$ scan swath (49 rays per scan) and continuous coverage along the GPM-CO path. Only the matched scan (MS) region of this swath (as shown in Figure 1) is used (central $120 \mathrm{~km} /$ 25 rays) to ensure the use of coincident $\mathrm{Ku}-$ and $\mathrm{Ka}-$ band measurements.

\subsection{Radarnet Data}

The Radarnet composite product from the 18 GBI radars is available upon request from [10]. An example of the data is shown in Figure 1. Individual radar scans contribute to the $1 \mathrm{~km}, 5$ minute resolution composite if they ended within two minutes prior to or 3 minutes after the composite time stamp [personal communication with S. Best, 2017]. Polarimetric upgrades to the UK radars (not the ROI radars) took place during the study time period: each upgrade took approximately 6 months before the radar measured precipitation again and no two radars within the same vicinity were upgraded together. 5 radars were fully upgraded prior to the study, 8 were upgraded during the course of the study, and 3 radars were not fully upgraded by the end of the study. More details on the upgrades are provided at https://www.metoffice.gov.uk/research/weather/observationsresearch/weather-radar-network-renewal-project-timescales.

\subsection{Collocation Methodology}

All $5 \mathrm{~km}$ GPM measurements within the Radarnet composite extents (Latitude: $46.5^{\circ}-61^{\circ}$; Longitude: $-13^{\circ}-4.5^{\circ}$ ) are used for collocation of the Radarnet $1 \mathrm{~km}$ product. Collocation of the Radarnet $1 \mathrm{~km}$ product is performed on a scan-byscan basis. Temporal collocation involves interpolating the

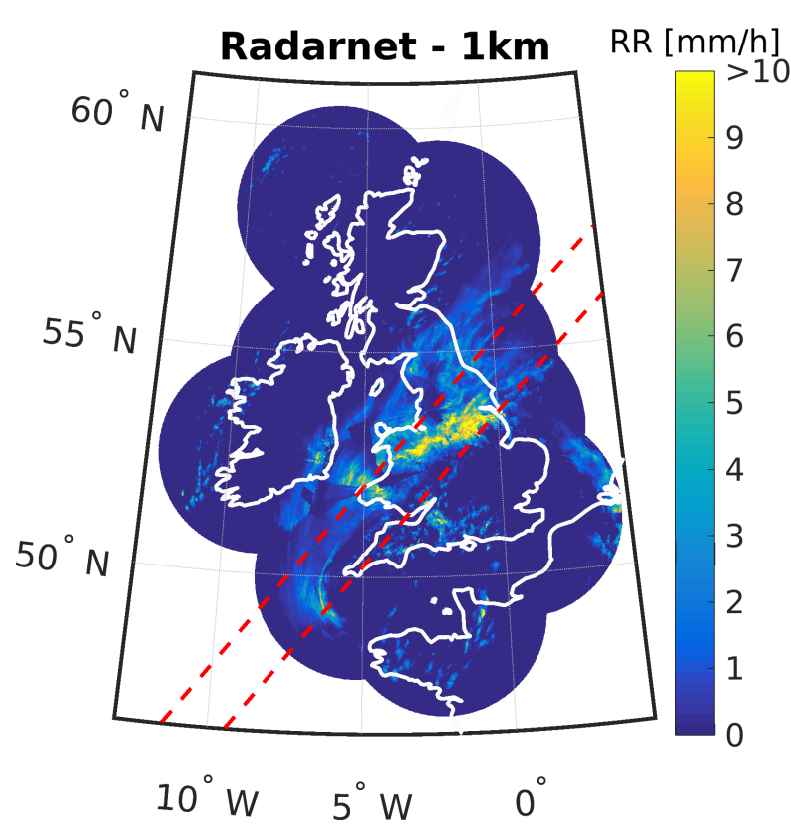

Fig. 1. An example of $1 \mathrm{~km}$ Radarnet composite product data from 21st November 2016, interpolated to a scan time near the centre of the high intensity event. The red dashed lines represent the edges of the DPR MS swath region.

two closest Radarnet data products to the DPR scan time, and spatial collocation of this data to each DPR ray pixel within a scan is performed using a weighted mean of all nearby 1 $\mathrm{km}$ pixels. The weighting corresponds to the DPR's 2-way antenna gain.

With the Radarnet data pixels collocated to $5 \mathrm{~km}$ resolution, quality-controlled data is ensured by two criteria, similar to [11]. The criteria are that $5 \mathrm{~km}$ pixels produced from $1 \mathrm{~km}$ Radarnet pixels where more than $20 \%$ lack a rain rate estimate are removed, and that $5 \mathrm{~km}$ pixels produced with less than 16 Radarnet $1 \mathrm{~km}$ pixels within a $2.5 \mathrm{~km}$ radius of the $5 \mathrm{~km}$ pixel centre are excluded. All corresponding GPM pixels are also removed for a fair comparison. Finally, a mask is used to compare the DPR, CMB and Radarnet products; only data pixels in which all the products have a rain rate of 0.2 $\mathrm{mmh}^{-1}$ or more are included. This rain rate corresponds to the DPR minimum detection threshold. Masked data are compared using normalised bias, normalised standard deviation, and correlation statistics. The statistics are normalised with respect to the mean Radarnet rain rate for the data. A positive bias means that the GPM product estimates higher rain rates than the Radarnet product, and vice versa.

\section{COMPARISON RESULTS AND DISCUSSION}

Comparison of the GPM products to the Radarnet product at $5 \mathrm{~km}$ resolution is shown in Figure 2, with a sample size of 575512. The corresponding statistical results are shown in 

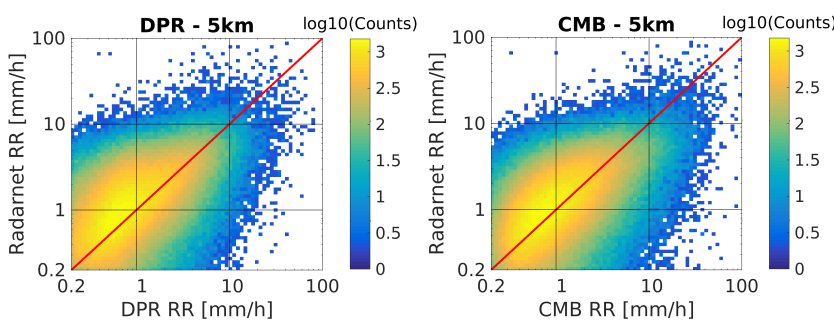

Fig. 2. Density scatterplots of the masked GPM products versus the masked Radarnet product at $5 \mathrm{~km}$ resolution (DPR left; CMB - right).

Table 1. The results suggest that both the GPM instruments underestimate rain rates in comparison to the Met Office radars. The combined DPR-GMI product appears to be more in line with the Radarnet product according to the magnitude of the bias $(-2 \%)$ and higher correlation (0.49). The normalised standard deviation for both products is very large, to the extent that the the standard deviation surpasses the mean Radarnet-measured rain rate over GBI. This suggests that the normalised biases are because of the cancellation of many overestimates and underestimates as is portrayed in Figure 2. In comparison to the Western Europe study [7], the two products exhibit better biases but lesser correlations.

These results suggest that the level of agreement between the GPM and the Radarnet products is highly variable, and the reasons for such inconsistencies need to be investigated. The authors of this paper plan to research the seasonal, rainfall intensity, spatial, and non-uniform beam filling variabilities of the results to identify under what conditions there are good (and poor) agreement between the different instruments. Investigation of these variabilities will help to identify issues with the processing of GPM and Radarnet measurements such as the orographic enhancement of rainfall and the variability of rainfall within pixel footprints. In particular, assessment of the spatial variability of biases and standard deviations with respect to the ground-based radar location will be important as the ground-based radars may have artefacts, e.g. due to the vertical profile of reflectivity which may explain some of the GPM overestimations at positions corresponding to long ranges from the Met Office radars.

\section{CONCLUSION}

Instantaneous surface rain rate products produced from spaceborne and ground-based measurements over Great Britain and Ireland within a three year period have been compared. The space-borne GPM DPR and DPR-GMI combined products have been found to underestimate rainfall intensities with respect to the ground-based Radarnet product. However, these results have been found to be highly variable, possibly due to seasonal, spatial, rainfall intensity and non-uniform beam filling effects. Work is being conducted to understand the vari-
Table 1. Statistics for the comparison of the GPM products to the Radarnet product at $5 \mathrm{~km}$ resolution.

\begin{tabular}{cccc}
\hline Satellite Product & Bias [\%] & SD [\%] & Correlation \\
\hline DPR & -17 & 133 & 0.42 \\
\hline CMB & -2 & 131 & 0.49 \\
\hline
\end{tabular}

ability of the results.

\section{ACKNOWLEDGEMENTS}

The authors would like to thank Steven Best of the Met Office for the information he provided regarding the production of the Radarnet composite 5 minute, $1 \mathrm{~km}$ resolution data files via email communication. The version 5 (V05) level-2A DPR and level-2B CMB data were provided by the NASA/Goddard Space Flight Center and PPS, which develop and compute the version 5 (V05) level-2A DPR and level-2B CMB data as a contribution to GPM, and archived at the NASA GES DISC. The $1 \mathrm{~km}$ resolution UK composite rainfall data was provided by the Met Office Radarnet system and the Centre for Environmental Data Analysis. This research used the SPECTRE High Performance Computing Facility at the University of Leicester.

\section{REFERENCES}

[1] Arthur Y Hou, Ramesh K Kakar, Steven Neeck, Ardeshir A Azarbarzin, Christian D Kummerow, Masahiro Kojima, Riko Oki, Kenji Nakamura, and Toshio Iguchi, "The Global Precipitation Measurement Mission," Bulletin of the American Meteorological Society, vol. 95, no. 5, pp. 701-722, 2014.

[2] Joanne Simpson, C Kummerow, W-K Tao, and Robert F Adler, "On the Tropical Rainfall Measuring Mission (TRMM)," Meteorology and Atmospheric Physics, vol. 60, no. 1, pp. 19-36, 1996.

[3] Gail Skofronick-Jackson, Walter A Petersen, Wesley Berg, Chris Kidd, Erich F Stocker, Dalia B Kirschbaum, Ramesh Kakar, Scott A Braun, George J Huffman, Toshio Iguchi, et al., "The Global Precipitation Measurement (GPM) Mission for Science and Society," Bulletin of the American Meteorological Society, vol. 98, no. 8, pp. 1679-1695, 2017.

[4] Dawn Harrison, Katie Norman, Tim Darlington, Donal Adams, Nawal Husnoo, Caroline Sandford, and Steven Best, "14B.2 The evolution of the Met Office radar data quality control and product generation system: Radarnet," in 37th Conference on Radar Meteorology, American Meteorological Society, Ed., 2015. 
[5] D. L. Harrison, S. J. Driscoll, and M. Kitchen, "Improving precipitation estimates from weather radar using quality control and correction techniques," October 1998.

[6] Jonathan G Fairman, David M Schultz, Daniel J Kirshbaum, Suzanne L Gray, and Andrew I Barrett, "A radarbased rainfall climatology of Great Britain and Ireland," Weather, vol. 70, no. 5, pp. 153-158, 2015.

[7] C Kidd, J Tan, P-E Kirstetter, and WA Petersen, "Validation of the Version 05 Level 2 precipitation products from the GPM Core Observatory and constellation satellite sensors," Quarterly Journal of the Royal Meteorological Society, 2017, DOI:10.1002/qj.3175.

[8] NASA, "GPM 2A-DPR and 2B-CMB, version 5 (V05)," NASA's Precipitation Processing System, 2017, Subset used: May 2014 - April 2017, accessed 23 October, 2017, https://pmm.nasa.gov/dataaccess/downloads/gpm.
[9] NASA, "Precipitation Processing System Global Precipitation Measurement - File Specification for GPM Products - Version 1.08 TKIO 3.60.4," 2014, accessed 6 April, 2017, https://storm.pps.eosdis.nasa.gov/storm/filespec.GPM. V1.pdf.

[10] Met Office, "Met Office Rain Radar Data from the NIMROD System," 2003, NCAS British Atmospheric Data Centre, Subset used: May 2014 - April 2017, accessed 19 October, 2017, http://catalogue.ceda.ac.uk/uuid/82adec1f896af616911 $2 \mathrm{~d} 09 \mathrm{cc} 1174499$.

[11] Pierre-Emmanuel Kirstetter, Y Hong, JJ Gourley, S Chen, Z Flamig, J Zhang, M Schwaller, W Petersen, and Eyal Amitai, "Toward a framework for systematic error modeling of spaceborne precipitation radar with NOAA/NSSL ground radar-based National Mosaic QPE," Journal of Hydrometeorology, vol. 13, no. 4, pp. 1285-1300, 2012. 